\title{
Erratum to: Cooperative magnetophoresis of superparamagnetic colloids: theoretical aspects
}

\author{
J. Faraudo • J. Camacho
}

Published online: 12 July 2011

(C) Springer-Verlag 2011

Erratum to: Colloid Polym Sci (2010) 288:207-215

DOI 10.1007/s00396-009-2107-z

We have found a missing numerical factor in Eq.(9) which defines the energy scale $U_{0}$. The correct definition, employed in all calculations reported in our paper [1], is:

$U_{0}=\frac{\mu_{0}}{4 \pi} \frac{m^{2}}{(2 R)^{3}}=\frac{1}{2} k_{B} T\left[\frac{\lambda_{B}^{m}}{2 R}\right]^{3}$

Also there is an error in the page numbers of Ref. [2]. The correct page numbers are given below. We apologize for any inconvenience this may cause.

\section{References}

1. Faraudo J, Camacho J (2010) Cooperative magnetophoresis of superparamagnetic colloids: theoretical aspects. Colloid Polym Sci 288:207-215

2. Taboada E, Solanas R, Rodríguez E, Weissleder R, Roig A (2009) Supercritial-fluid-assisted one-pot synthesis of biocom-patible core $(\gamma-\mathrm{Fe} 2 \mathrm{O} 3) /$ shell$(\mathrm{SiO} 2)$ nanoparticles as high relaxivity T2-contrast agents for magnetic resonance imaging. Adv Func Mat 19:2319-2324

The online version of the original article can be found at http://dx.doi. org/10.1007/s00396-009-2107-z.

J. Faraudo $(\bowtie)$

Institut de Ciència de Materials de Barcelona (ICMAB-CSIC),

Campus UAB,

E-08193 Bellaterra, Spain

e-mail: jfaraudo@icmab.es

J. Camacho

Departament de Física, Universitat Autònoma de Barcelona,

Campus UAB,

E-08193 Bellaterra, Spain

e-mail: juan.camacho@uab.es 